\title{
Secretion properties, clearance, and therapy in airway disease
}

Bruce K Rubin

\begin{abstract}
Chronic airway diseases like cystic fibrosis, chronic bronchitis, asthma, diffuse panbronchiolitis, and bronchiectasis are all associated with chronic inflammation. The airway mucosa responds to infection and inflammation in part by surface mucous (goblet) cell and submucosal gland hyperplasia and hypertrophy with mucus hypersecretion. Products of inflammation including neutrophil derived DNA and filamentous actin, effete cells, bacteria, and cell debris all contribute to mucus purulence and, when this is expectorated it is called sputum. Mucus is usually cleared by ciliary movement, and sputum is cleared by cough.

These airway diseases each are associated with the production of mucus and sputum with characteristic composition, polymer structure, and biophysical properties. These properties change with the progress of the disease making it possible to use sputum analysis to identify the potential cause and severity of airway diseases. This information has also been important for the development of effective mucoactive therapy to promote airway hygiene.
\end{abstract}

\section{Review}

Introduction

Mucus clearance is a primary defense mechanism of the lung. Mucus is a barrier to airway water loss and microbial invasion and it is essential for the clearance of inhaled foreign matter [1]. Mucus is a viscoelastic gel consisting of water and high molecular weight glycoproteins, called mucins, mixed with serum and cellular proteins and lipids. The principal gel-forming mucins in the human airway are MUC5AC and MUC5B [2,3]. There are variable amounts of cell debris and particulate matter in normal mucus. Sputum is expectorated mucus mixed with inflammatory cells, cellular debris, DNA and F-actin, as well as bacteria [4] (Figure 1). In cystic fibrosis $(\mathrm{CF})$, there is almost no intact mucin in the airway secretions [5] due to mucin degradation by serine proteases [6]. These secretions are biochemically identical to pus.

Respiratory mucus is a mixture of submucous gland, goblet cell, and epithelial cell secretions [7]. Submucous glands are innervated by cholinergic, adrenergic, and nonadrenergic, non-cholinergic nerves [8]. Glandular secretions are thought to be the major constituent of respiratory mucus in health. Goblet cells expel their contents when exposed to irritants and appear to be inflammatory effector

Correspondence: brubin@vcu.edu

Department of Pediatrics, Children's Hospital of Richmond at VCU, Virginia Commonwealth University School of Medicine, 1001 East Marshall St., P.O. Box 980646, Richmond, VA 23298, USA cells as well. Epithelial cells produce much of the periciliary fluid layer by active ion transport [9].

Mucus is usually cleared by airflow and ciliary interactions while sputum is primarily cleared by cough. Secretion clearance depends upon mucus properties such as viscoelasticity and adhesiveness, serous fluid properties, and ciliary function. In order to understand how impaired mucus clearance is related to respiratory disease and to develop new therapies, we study each of these properties as a function of disease type, disease severity, and therapy [10].

\section{Properties of mucus \\ Rheology}

Viscosity is the loss of energy (loss modulus) from an object moving through a substance and thus the resistance to flow. This is a property of fluids and a Newtonian or ideal fluid can be rheologically defined by viscosity alone. Elasticity is the storage modulus and a property of solids. Pseudoplastic gels, like mucus gels are viscoelastic. Both viscosity and elasticity are essential for clearance [11]. While ciliary clearance can be impeded by high viscosity, cough clearance in increased when the gel is viscous and abhesive (not sticky) $[12,13]$.

\section{Surface properties}

Cohesivity is the ability of a substance to bind to itself or form threads under conditions of attachment deformation. 

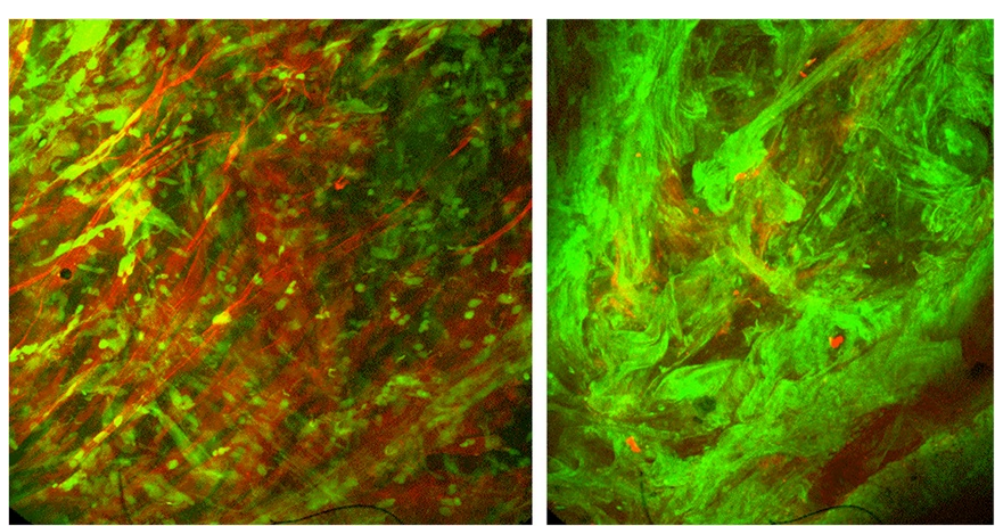

Figure 1 Confocal micrograph showing mucin polymers (Texas red-UEA) and DNA polymers (Green - YoYo1) in bronchitis (left) and cystic fibrosis (right) sputum.

Wettability is the surface energy at a solid-sputum-air interface and is measured using the sessile drop technique. Interfacial tension is the interfacial or surface energy between a gel and liquid or gas surface. This is also called surface tension when the interface is between an ideal liquid and gas [13].

Adhesivity is the ability to bond to a solid surface measured as the force of separation between one or more solid surfaces and the adhesive material. The work of adhesion is calculated from the contact angle and interfacial tension and tenacity or work of distraction is the product of cohesiveness and adhesiveness. Tenacity is the major physical determinant of cough transportability [14].

\section{The transport properties of secretions}

Cough transportability A simulated cough machine is used to measure the airflow-dependent clearability of sputum. Using this device, we have shown that cough clearability of secretions increases with greater mucus depth and the presence of periciliary fluid [15].

\section{Ciliary function}

Ciliary action is dependent on temperature, mucus gel and periciliary fluid hydration, mucus loading, and ciliary beat frequency, coordination, and power. Ciliary dysfunction can be due to congenital ciliary abnormalities such as primary ciliary dyskinesia [16], or caused by irritants, allergens, smoke, or infection. Mucociliary clearance is impaired both by mucus viscoelasticity and by mucus adhesiveness [17].

\section{Conditions associated with mucus clearance defects Primary ciliary dyskinesia (PCD)}

PCD leads to ineffective mucociliary clearance and bronchiectasis. These patients expectorate sputum with biophysical and clearance properties similar to sputum from persons with CF [18]. Similar to CF, there are high concentrations of inflammatory mediators in PCD sputum but a greater amount of intact mucin is present. It is thought that the much slower progression of disease in persons with $\mathrm{PCD}$ when compared with $\mathrm{CF}$ is probably due to conditions in the CF airway, which promote the growth of bacterial biofilms and chronic inflammation [19].

\section{Cystic fibrosis (CF)}

Sputum from persons with CF has not been shown to be abnormally thick, dehydrated, or viscous but has viscosity comparable to sputum from patients with bronchiectasis and less than that of persons with chronic bronchitis or severe asthma [20]. There are compelling data suggesting that surfactant abnormalities in CF sputum lead to secretions that are exceedingly adhesive [21]. Because of the CF abnormality in transepithelial chloride transport, it is likely that dysregulation of the depth and composition of the periciliary fluid layer may play a role in impeding mucus transport in the CF airway [22].

Data demonstrate that there is little intact mucin in the CF airway; even in young children with mild disease [5]. However the ability to secrete mucin appears to be intact and transiently expressed during periods of increased inflammation such as during an exacerbation of pulmonary infection [23].

\section{Fucosidosis (congenital absence of alpha-L-fucosidase)}

Fewer than 100 patients have been reported with this autosomal recessive defect due to absence of the gene for alpha-L-fucosidase on chromosome 1. Fucose and sialic acid are the predominant terminal sugars on mucin glycoprotein chains. We have described extremely watery mucus from the airway of a child with fucosidosis, and this mucus could not be easily cleared by cough or ciliary mechanisms [24]. The abnormal viscoelasticity is probably explained by defective mucus cross-linking. 


\section{Allergy and asthma}

Inhalation of Ascaris antigen in low dose releases a large volume of watery mucus in sensitized dogs. When sufficient antigen is inhaled to cause bronchoconstriction, rigid, poorly cleared mucus is released [25]. This biphasic response is similar to that seen with the administration of cholinergic drugs and can be blocked with anticholinergics medications. A similar response can be seen in adults with acute asthma [26].

Mucus from patients with acute severe asthma has extremely high viscosity and patients who die during an asthmatic attack have extensive mucus plugging of their airways [27]. This is probably due to an abnormal secondary structure of the highly mucin enriched secretion $[28,29]$.

Patients with asthma who have chronic cough and sputum production have worse clinical control as measured by the asthma control questionnaire (ACQ) and more frequent exacerbations [26]. Helper T-cell type 2 (Th2) cytokines, including interleukin (IL)-13, are implicated in mucus production and goblet cell hyperplasia in asthma and IL-13 induces goblet cell hyperplasia with mucus hypersecretion in human airway epithelial cells. Airway goblet cell hyperplasia induced by IL-13 is steroid insensitive [30] but can be attenuated by 14- and 15member macrolide antibiotics [31]. These data are consistent with clinical reports in steroid-resistant asthmatics [32]. Increased IL-13 mRNA expression is not reduced by steroid inhalation and under some circumstances; steroids further increase IL-13 induced mucin production [33].

Persons with severe asthma also have high levels of secretory phospholipases A2 (sPLA2) in their airway and bronchial lavage fluid. sPLA2 induce dramatic mucus hypersecretion, termed secretory hyperresponsiveness [34], cysteinyl leukotriene production, and hydrolyze airway surfactant [35].

\section{Irritant exposure, smoking, bronchitis, and lung cancer}

Acute exposure to irritants causes hypersecretion of watery, easily cleared mucus. Similarly, asymptomatic smokers produce watery mucus that is transported faster by cilia than normal mucus [36]. However in vivo mucociliary clearance is not increased in the light smoker probably because of epithelial damage.

Epidemiological studies show a correlation between COPD progression and chronic cough with sputum production. In The Copenhagen City Heart Study data analysis suggests that chronic mucus hypersecretion was significantly associated with both greater FEV1 decline and an increased risk of hospitalization [37]. It has been postulated that impaired mucus clearance in chronic smokers can lead to prolonged contact of irritants with the airway epithelium and so promote cellular metaplasia and cancer $[38,39]$.

\section{Non CF bronchiectasis}

The biophysical properties of sputum from children with bronchiectasis are different from those of subjects with CF or chronic bronchitis [40]. This leads to relatively greater cough transportability compared to CF sputum. These sputum properties may explain, in part, the different clinical course of children with idiopathic bronchiectasis compared to children with CF.

\section{Plastic bronchitis}

Plastic bronchitis is a rare disease in which there is the formation of large gelatinous or rigid branching airway casts. Plastic bronchitis has been associated with conditions as diverse as congenital heart disease almost always after palliative surgery, abnormalities of pulmonary lymphatic flow, sickle cell disease acute chest syndrome, and perhaps with hypersecretory severe asthma. The bronchial casts contain little or no DNA and consist almost entirely of fibrin and abnormally cross-linked mucin; similar to fatal asthma [41]. Because of the rarity of this disease, there are no reported randomized clinical trials of therapy although anecdotal case reports have suggested some benefit with the use of tPA acutely as a fibrinolytic agent, heparin aerosol chronically, presumably to inhibit Tissue Factor, and low dose macrolides to decrease excessive mucus production [42].

\section{Therapy of mucus clearance disorders}

The classification of mucoactive medications by presumed mechanisms of action is given in Table 1 [43]. An overview of these medications and evidence of their effectiveness (or lack of effectiveness) is presented below.

Expectorants are thought to increase the hydration of sputum either by the direct addition of water or by stimulation of water secretion into the airway [44]. Expectorants do not directly improve mucociliary clearance. The expectorants include water, guaifenesin, and the iodide containing medications. Despite widespread use of these agents, there are no well-controlled clinical trials that support their use, while randomized controlled trials have generally shown these medications to be ineffective [45-47].

Studies suggest that the inhalation of $7 \%$ saline can increase expectoration and improve pulmonary function in patients with CF [48]. This is probably due, in part, to stimulation of both water and mucus secretion into the hyperosmolar environment [49]. Mannitol, a sugar, has also been administered as a dry powder aerosol for the therapy of CF and non-CF bronchiectasis [50,51]. Use of hypertonic saline is limited, in part, because of inflammation, cough, and airflow limitation (bronchospasm) in some patients [48]. Data suggest that hypertonic saline is less effective than dornase alfa (Pulmozyme) in improving pulmonary function in persons with CF [52]. 
Table 1 Mucoactive medications and their presumed actions

\begin{tabular}{|c|c|}
\hline Mucoactive agent & Potential mechanisms of action \\
\hline \multicolumn{2}{|l|}{ Expectorants } \\
\hline \multicolumn{2}{|l|}{ Mannitol powder } \\
\hline Hypertonic saline & $\begin{array}{l}\text { Increases secretion volume and } \\
\text { perhaps hydration }\end{array}$ \\
\hline \multicolumn{2}{|l|}{ Classical mucolytics } \\
\hline $\mathrm{N}$-acetylcysteine & $\begin{array}{l}\text { Severs disulfide bond linking mucin } \\
\text { oligomers }\end{array}$ \\
\hline Ambroxil & $\begin{array}{l}\text { Increases chloride secretion and } \\
\text { severs disulfide bonds }\end{array}$ \\
\hline \multicolumn{2}{|l|}{ Peptide mucolytics } \\
\hline Dornase alfa & $\begin{array}{l}\text { Hydrolyzes DNA polymer with } \\
\text { reduction in DNA length }\end{array}$ \\
\hline Gelsolin or Thymosin $\beta_{4}$ & Depolymerizes F-actin \\
\hline \multicolumn{2}{|c|}{ Non-destructive mucolytics } \\
\hline Dextran & Breaks hydrogen bonds \\
\hline \multicolumn{2}{|l|}{ Mucoregulatory agents } \\
\hline Anticholinergic agents & $\begin{array}{l}\text { Decreases volume of stimulated } \\
\text { secretions }\end{array}$ \\
\hline Glucocorticoids & $\begin{array}{l}\text { Decreases airway inflammation } \\
\text { and mucin secretion }\end{array}$ \\
\hline Indomethacin & Decrease airway inflammation \\
\hline Macrolide antibiotics & $\begin{array}{l}\text { Decreases airway inflammation } \\
\text { and mucin secretion }\end{array}$ \\
\hline \multicolumn{2}{|c|}{ Cough clearance promoters } \\
\hline Bronchodilators & $\begin{array}{l}\text { Can improve cough by increasing } \\
\text { expiratory flow }\end{array}$ \\
\hline Surfactants & Decreases sputum adhesiveness \\
\hline
\end{tabular}

Mucociliary clearance depends in part, on the viscoelasticity of the secretions. Mucolytics reduce sputum viscosity by disrupting polymer networks in the secretions. Classic mucolytic agents work by severing disulfide bonds, binding calcium, and depolymerizing mucopolysaccharides. Agents containing free sulfhydryl groups reduce the disulfide bridges interconnecting the mucin molecules. These agents include $\mathrm{N}$-acetyl-L-cysteine (NAC) and similar drugs. There are no data that support the clinical use of aerosol NAC for the therapy of lung disease [53]. A large, prospective, randomized trial in subjects with chronic bronchitis showed no benefit of high dose oral NAC over placebo [54]. Orally administered NAC does not penetrate into the airway or bronchial lavage fluid [55] and inhaled NAC ( $\mathrm{pH} 2.2)$ can cause bronchospasm and airway inflammation [56].

Sputum contains products of inflammation including DNA and filamentous actin (F-actin) polymers formed [4]. DNA and F-actin copolymerize to form a rigid network entangled with the mucin gel. Peptide mucolytics degrade these abnormal polymers. Dornase alfa (Pulmozyme,
Genentech, South San Francisco, CA) is widely used for the treatment of CF airway disease and this peptide mucolytic has been shown to improve pulmonary function and decrease the frequency of pulmonary exacerbations when used daily as an aerosol $[57,58]$. However dornase has not been shown to be effective in treating any pulmonary disease other than CF [59]. The G-actin sequestering and F-actin depolymerizing peptide, thymosin $\beta 4$ has also shown promise in vitro as a peptide mucolytic and potentially an anti-inflammatory agent for the treatment of CF [60].

For cough to be effective there must be sufficient airflow to detach sputum from the epithelium and to mobilize secretions so that they can be expectorated. Mucokinetic agents improve the cough clearance of secretions, either by increasing airflow or by altering the sputum-epithelium interaction. By this definition, bronchodilators can be considered mucokinetic agents but only in patients who have a significant improvement in airflow with bronchodilator therapy.

Mucus adheres to the cilia and epithelium. It is thought that a bronchial surfactant layer promotes spreading of the mucous layer and efficient transfer of energy from beating cilia to the mucus preventing entanglement of the cilia in the mucus. Decreasing sputum tenacity increases sputum cough transportability in CF or chronic bronchitis. Some of the expectorant activity of classic mucolytics may be attributed un-sticking mucus from the airway surface.

Surfactant facilitates the spreading of the mucus across the tips of the cilia and it augments the efficient transfer of energy from the cilia to the mucous layer [13]. Surfactant therapy improves secretion transport in newborns with respiratory distress syndrome [61] and clinical trials with an aerosol surfactant in chronic bronchitis showed an improvement in pulmonary function and a decrease in trapped thoracic gas. This was associated with increased sputum mucociliary transportability [62].

Mucoregulatory agents inhibit mucus production or mucus secretion. Anticholinergic medications are the most well studied agents in this class. Anticholinergics can reduce the volume of stimulated secretions without increasing viscosity [63]. The topical anticholinergic bronchodilator, oxitropium bromide, has been shown to decrease the volume of secretions in patients with chronic bronchitis without changing mucus viscoelasticity [64]. The longacting anticholinergic agent, tiotropium bromide, has kinetic selectivity for both the M1 and M3 receptor types over the M2 (auto-inhibitory) receptor [63]. In one study with COPD patients without exacerbations, tiotropium bromide treatment did not improve tracheobronchial clearance when compared with placebo [65].

Inflammation leads to mucous gland hyperplasia and many inflammatory mediators are potent secretagogues. Indomethacin has been administered by aerosol for the 
treatment of mucus hypersecretion in persons with diffuse panbronchiolitis, chronic bronchitis, or bronchiectasis [66]. Fourteen and 15-member macrolide antibiotics can reduce airway mucin secretion by virtue of their immunomodulatory activity [67-69]. This action is unrelated to the antibacterial activity and appears to be mediated by modulation of the ERK 1/2 pathway [70,71]. Erythromycin and clarithromycin have been successfully used to treat mucus hypersecretion in patients with bronchorrhea, asthma, and sinusitis [72]. Low dose and long term azithromycin therapy is now routinely used for the therapy of CF [73].

\section{The clinical use of mucoactive therapy}

The principal indication for mucoactive therapy is to reduce airway obstruction by abnormal secretions. By decreasing the volume of secretions, gas trapping is reduced and there is improved performance of the muscles of respiration. Therapy should first be directed at decreasing infection and inflammation and minimizing exposure to irritants. The use of mucoactive medications and therapy to decrease mucus production and improve sputum expectoration can then be considered. Chest physical therapy, with or without accessory devices is usually prescribed along with the use of mucoactive medications [74].

Patients most likely to benefit from mucoactive therapy usually have a history of increased sputum expectoration and preserved airflow. Patients with acute mucus retention such as acute bronchitis or exacerbations of CF appear to be less responsive to mucoactive medications than stable patients. This may be due to decreased airflow caused both by the increase in infection and to muscular weakness in association with the pulmonary exacerbation, further reducing airflow dependent clearance mechanisms.

The effectiveness of therapy in an individual patient can be difficult to assess. When the patient feels better and there is an improvement in airflow or a reduction in trapped thoracic gas benefit is clear. However, changes in FEV1 poorly reflect clinical improvement with mucoactive therapy. Intuitively, one might expect that expectorated sputum volume would be a good way to assess the effectiveness of therapy but the expectorated sputum volume relates poorly, at best, to improvement in pulmonary function or the clinical status of the patient [75].

The scientific evaluation of secretion properties and response to therapy should enable the development of effective mucoactive therapy and allow us to better determine which patients are most likely to benefit from specific therapy.

\section{Conclusion}

Many airway diseases are associated with the production of mucus and sputum with characteristic composition, polymer structure, and biophysical properties. These properties change with the progress of the disease making it possible to use sputum analysis to identify the potential cause and severity of airway diseases. This information has also been important for the development of effective mucoactive therapy to promote airway hygiene.

\section{Competing interests}

The author holds patents on the use of aerosol surfactant as a mucokinetic agent and aerosol dapsone for regulation of mucus hypersecretion. The author's research laboratory studies novel therapies for treating mucus clearance disorders of the nose the airways. Many of these studies are funded by pharmaceutical companies. The author also provides expert consultation for the development of mucoactive therapies.

Received: 16 January 2014 Accepted: 19 February 2014

Published: 10 March 2014

\section{References}

1. Rogers DF: Physiology of airway mucus secretion and pathophysiology of hypersecretion. Respir Care 2007, 52:1134-1146.

2. Lopez-Vidriero MT: Airway mucus: production and composition. Chest 1981, 80(Suppl):799-804.

3. Voynow JA, Rubin BK: Mucins, mucus, and airway secretions. CHEST 2009, 135:505-512.

4. Tomkiewicz RP, Kishioka C, Freeman J, Rubin BK: DNA and actin filament ultrastructure in cystic fibrosis sputum. In Cilia, Mucus and Mucociliary Interactions. Edited by Baum G. New York: Marcel Dekker; 1998:333-341.

5. Henke MO, Renner A, Huber RM, Seeds MC, Rubin BK: MUC5AC and MUC5B mucins are decreased in cystic fibrosis airway secretions. Am J Respir Cell Mol Biol 2004, 31:86-91.

6. Henke MO, John G, Rheineck C, Chillappagari S, Naehrlich L, Rubin BK: Serine proteases degrade airway mucins in cystic fibrosis. Infect Immun 2011, 79(8):3438-3444.

7. Wanner A, Salathé M, O'Riordan TG: Mucociliary clearance in the airways. Am J Respir Crit Care Med 1996, 154:1868-1902.

8. Kishioka C, Okamoto K, Kim JS, Rubin BK: Regulation of secretion from mucous and serous cells in the excised ferret trachea. Resp Physio/ 2001, 126:163-171.

9. Boucher RC: State of the art: human airway ion transport. Am J Respir Crit Care Med 1994, 150:271-281. and 581-593.

10. King M, Rubin BK: Pharmacological approaches to discovery and development of new mucolytic agents. Advanced Drug Delivery Rev 2002, 54:1475-1490.

11. King M, Rubin BK: Mucus rheology, relationship with transport. In Airway secretion: Physiological Bases for the Control of Mucus Hypersecretion. Edited by Takishima T. New York: Marcel Dekker, Inc; 1994:283-314.

12. King $M$, Brock $G$, Lundell C: Clearance of mucus by simulated cough. J Appl Physiol 1985, 58:1776-1782.

13. Rubin BK: Surface properties of respiratory secretions: relationship to mucus transport. In Cilia, Mucus, and Mucociliary Interactions. Edited by Baum G. New York: Marcel Dekker; 1998:317-324.

14. Albers GM, Tomkiewicz RP, May MK, Ramirez OE, Rubin BK: Ring distraction technique for measuring surface tension of sputum: relationship to sputum clearability. J Appl Physiol 1996, 81:2690-2695.

15. Agarwal M, King M, Rubin BK, Shukla JB: Mucus transport in a miniaturized simulated cough machine: effect of constriction and serous layer simulant. Biorheology 1988, 26:977-988.

16. Rubin BK: Immotile cilia syndrome (primary ciliary dyskinesia) and airways inflammation. Clin Chest Med 1988, 9:657-668.

17. Rubin BK, Ramirez O, King M: Mucus-depleted frog palate as a model for the study of mucociliary clearance. J Appl Physiol 1990, 69:424-429.

18. Bush A, Payne D, Pike S, Jenkins G, Henke MO, Rubin BK: Mucus properties in children with primary ciliary dyskinesia: comparison with cystic fibrosis. Chest 2006, 129:118-123.

19. Rubin BK: CFTR is a modulator of airway inflammation. Am J Physiol Lung Cell and Molec Physiol 2008, 2:L381-L382.

20. Rubin BK: Mucus structure and properties in cystic fibrosis. Paed Resp Rev 2007, 8:1-7. 
21. Girod S, Galabert C, Lecuire A, Zahm JM, Puchelle E: Phospholipid composition and surface-active properties of tracheobronchial secretions from patients with cystic fibrosis and chronic obstructive pulmonary diseases. Pediatr Pulmonol 1992, 13:22-27.

22. Tarran R, Button B, Boucher RC: Regulation of normal and cystic fibrosis airway surface liquid volume by phasic shear stress. Annu Rev Physiol 2006, 68:543-561.

23. Henke MO, Gerrit J, Germann M, Lindemann H, Rubin BK: MUC5AC and MUC5B mucins increase in cystic fibrosis airway secretions during a pulmonary exacerbation. Am J Resp Crit Care Med 2007, 175:816-821.

24. Rubin BK, MacLeod PM, Sturgess JM, King M: Recurrent respiratory infections in a child with fucosidosis: Is the mucus too thin for effective transport? Ped Pulmonol 1991, 10:304-309.

25. King M, El-Azab J, Phillips DM, Angus GE: Antigen challenge and canine tracheal mucus. Int Arch Allergy Appl Immunol 1985, 77:337-342.

26. Rogers DF: Airway mucus hypersecretion in asthma: an undervalued pathology? Curr Opin Pharmacol 2004, 4:241-250.

27. Rubin BK, Tomkiewicz R, Fahy JV, Green FY: Histopathology of fatal asthma. Drowning in mucus. Pedes Pulmonol 2001, 23:88-895.

28. Sheehan JK, Richardson PS, Fung DC, Howard M, Thornton DJ: Analysis of respiratory mucus glycoproteins in asthma: a detailed study from a patient who died in status asthmaticus. Am J Respir Cell Mol Biol 1995, 13:748-756.

29. Kuyper LM, Pare PD, Hogg JC, Lambert RK, lonescu D, Woods R, Bai TR: Characterization of airway plugging in fatal asthma. Am J Med 2003, 115:6-11.

30. Kanoh S, Tanabe T, Rubin BK: IL-13-induced MUC5AC production and goblet cell differentiation is steroid resistant in human airway cells. Clin Exp Allergy 2011, 41:1747-1756

31. Tanabe T, Kanoh S, Tsushima K, Yamazaki Y, Kubo K, Rubin BK Clarithromycin inhibits interleukin-13-induced goblet cell hyperplasia in human airway cells. Am J Respir Cell Mol Biol 2011, 45:1075-1083.

32. Naseer T, Minshall EM, Leung DY, Laberge S, Ernst P, Martin RJ, Hamid Q: Expression of IL-12 and IL-13 mRNA in asthma and their modulation in response to steroid therapy. Am J Respir Crit Care Med 1997, 155:845-851.

33. Saha SK, Berry MA, Parker D, Siddiqui S, Morgan A, May R, Monk P, Bradding $P$, Wardlaw AJ, Pavord ID, Brightling CE: Increased sputum and bronchial biopsy IL-13 expression in severe asthma. J Allergy Clin Immunol 2008, 121:685-691.

34. Okamoto K, Kim JS, Rubin BK: Secretory phospholipases A2 stimulate mucus secretion, induce airway inflammation, and produce secretory hyperresponsiveness to neutrophil elastase in ferret trachea. Am J Physiol 2007, 292(1):L62-L67.

35. Hite RD, Seeds MC, Jacinto RB, Balasubramanian R, Waite M, Bass D: Hydrolysis of surfactant-associated phosphotidylcholine by mammalian secretory phospholipases A2. Am J Physiol 1998, 275(Lung Cell Mol Physiol 19):L740-L747.

36. Rubin BK, Ramirez O, Zayas JG, Finegan B, King M: Respiratory mucus from asymptomatic smokers is better hydrated and more easily cleared by mucociliary action. Am Rev Respir Dis 1992, 145:545-547.

37. Vestbo J, Prescott E, Lange P: Association of chronic mucus hypersecretion with FEV1 decline and chronic obstructive pulmonary disease morbidity. Copenhagen City Heart Study Group. Am J Respir Crit Care Med 1996, 153:1530-1535.

38. Fahy JV, Dickey BF: Airway mucus function and dysfunction. N Engl J Med 2010, 363:2233-2247.

39. Zayas JG, Rubin BK, York EL, Lien DC, King M: Bronchial mucus properties in lung cancer: relationship with site of lesion. Canadian Resp J 1999 6(3):246-252.

40. Redding GJ, Kishioka C, Martinez P, Rubin BK: Physical and transport properties of sputum from Alaskan native children with bronchiectasis. Chest 2008, 134:1129-1134.

41. Madsen P, Shah SA, Rubin BK: Plastic bronchitis: new insights and a classification scheme. Paediatr Respir Rev 2005, 6:292-300.

42. Rubin BK, Moskowitz WB: Plastic bronchitis. In the ERS Handbook of Paediatric Respiratory Medicine. Edited by Ernst E, Fabio M. Sheffield, UK: European Respiratory Society Publications; 2013:577-581.

43. Rubin BK: Taxonomy of mucoactive medications. In Therapy for Mucus Clearance Disorders. Edited by Rubin BK, van der Schans CP. New York: Marcel Dekker, Inc; 2004:129-146.

44. Rubin BK: Mucolytics, expectorants, and mucokinetic medications. Resp Care 2007, 52:859-865.
45. Jager EG: Double-blind, placebo-controlled clinical evaluation of guaimesal in outpatients. Clin Ther 1989, 11:341-362.

46. Rubin BK, Ramirez O, Ohar JA: lodinated glycerol has no effect on pulmonary function, symptom score, or sputum properties in patients with stable chronic bronchitis. Chest 1996, 109:348-352.

47. Hoffer-Schaefer A, Rozycki HJ, Yopp MA, Rubin BK: Guaifenesin has no effect on sputum volume or sputum properties in adolescents and adults with an acute respiratory tract infection. Resp Care 2014. (in press) PMID:24003241.

48. Wark PA, McDonald V, Jones AP: Nebulised hypertonic saline for cystic fibrosis. Cochrane Database Syst Rev 2005, 3, CD001506.

49. Kishioka C, Okamoto K, Kim JS, Rubin BK: Hyperosmolar solutions stimulate mucus secretion in the ferret trachea. Chest 2003, 124:306-313.

50. Daviskas E, Anderson SD, Gomes K, Briffa P, Cochrane B, Chan HK, Young IH, Rubin BK: Inhaled mannitol for the treatment of mucociliary dysfunction in patients with bronchiectasis - effect on lung function, health status and sputum. Respirology 2005, 10:46-56.

51. Daviskas E, Rubin BK: Effect of inhaled dry powder mannitol on mucus and its clearance. Expert Rev Respir Med 2013, 7:65-75.

52. Suri R, Metcalfe C, Lees B, Grieve R, Flather M, Normand C, Thompson S, Bush A, Wallis C: Comparison of hypertonic saline and alternate-day or daily recombinant human deoxyribonuclease in children with cystic fibrosis: a randomised trial. Lancet 2001, 20(358):1316-1321.

53. Rogers DF, Rubin BK: Mucolytics for COPD. In Chronic Obstructive Pulmonary Disease. Edited by Stockley RA, Steven R, Klaus R, Bartolome C. Oxford: Blackwell Publishing; 2006.

54. Decramer M, Rutten-van Mölken M, Dekhuiizen PN, Troosters T, van Herwaarden C, Pellegrino R, van Schayck CP, Olivieri D, Del Donno M, De Backer W, Lankhorst I, Ardia A: Effects of N-acetylcysteine on outcomes in chronic obstructive pulmonary disease (Bronchitis Randomized on NAC Cost-Utility Study, BRONCUS): a randomised placebo-controlled trial. Lancet 2005, 365:1552-1560.

55. Cotgreave IA, Eklund A, Larsson K, Moldeus PW: No penetration of orally administered $\mathrm{N}$-acetylcysteine into bronchoalveolar lavage fluid. Eur $J$ Respir Dis 1987, 70:73-77.

56. Dano G: Bronchospasm caused by acetylcysteine in children with bronchial asthma. Acta Allergol 1971, 26:181-190.

57. Fuchs HJ, Borowitz DS, Christiansen DH, Morris EM, Nash ML, Ramsey BW, Rosenstein BJ, Smith AL, Wohl ME: Effect of aerosolized recombinant human DNase on exacerbations of respiratory symptoms and on pulmonary function in patients with cystic fibrosis. The Pulmozyme Study Group. N Engl J Med 1994, 331:637-642.

58. Laube BL, Auci RM, Shields DE, Christiansen DH, Lucas MK, Fuchs HJ, Rosenstein BJ: Effect of rhDNase on airflow obstruction and mucociliary clearance in cystic fibrosis. Am J Respir Crit Care Med 1996, 153:752-760.

59. Rubin BK: Who will benefit from DNase? Pediatr Pulmonol 1999, 27:3-4.

60. Rubin BK, Kater AP, Goldstein AL: Thymosin $\beta 4$ sequesters actin in cystic fibrosis sputum and decreases sputum cohesivity in vitro. Chest 2006, 130:1433-1440.

61. Rubin BK, Ramirez O, King M: Mucus rheology and transport in neonatal respiratory distress syndrome and the effect of surfactant therapy. Chest 1992, 101:1080-1085.

62. Anzueto A, Jubran A, Ohar JA, Piquette CA, Rennard SI, Colice G, Pattishall EN, Barrett J, Engle M, Perret KA, Rubin BK: Effects of aerosolized surfactant in patients with stable chronic bronchitis. A prospective randomized controlled trial. J Am Med Assoc 1997, 278:1426-1431.

63. Bateman ED, Rennard S, Barnes PJ, Dicpinigaitis PV, Gosens R, Gross NJ Nadel JA, Pfeifer M, Racké K, Rabe KF, Rubin BK, Welte T, Wessler I: Alternative mechanisms for tiotropium. Pulm Pharm Therapeutics 2009, 22:533-542.

64. Tamaoki J, Chiyotani A, Tagaya E, Sakai N, Konno K: Effect of long term treatment with oxitropium bromide on airway secretion in chronic bronchitis and diffuse panbronchiolitis. Thorax 1994, 49:545-548.

65. Hasani A, Toms N, Agnew JE, Sarno M, Harrison AJ, Dilworth P: The effect of inhaled tiotropium bromide on lung mucociliary clearance in patients with COPD. Chest 2004, 125:1726-1734.

66. Tamaoki J, Chiyotani A, Kobayashi K, Sakai N, Kanemura T, Takizawa T: Effect of indomethacin on bronchorrhea in patients with chronic bronchitis, diffuse panbronchiolitis, or bronchiectasis. Am Rev Respir Dis 1992, 145:548-552. 
67. López-Boado YS, Rubin BK: Macrolides as immunomodulatory medications for the therapy of chronic lung diseases. Curr Opinion Pharmacol 2008, 8:286-289.

68. Rubin BK, Tamaoki J: Macrolide antibiotics as biological response modifiers. Curr Opin Investig Drugs 2000, 1:169-172.

69. Rubin BK: Immunomodulatory properties of macrolides: overview and historical perspective. Am J Med 2004, 117:2S-4S.

70. Shinkai M, Park CS, Rubin BK: Immunomodulatory effects of macrolide antibiotics. Clin Pulm Med 2005, 12:341-349.

71. Shinkai M, Foster GH, Rubin BK: Macrolide antibiotics modulate ERK phosphorylation and IL-8 and GM-CSF production by human bronchial epithelial cells. Am J Physiol 2006, 290:L75-L85.

72. Rubin BK, Henke MO: Immunomodulatory activity and effectiveness of macrolides in chronic airway disease. Chest 2004, 125(2 Suppl):70S-785.

73. Southern KW, Barker PM, Solis A: Macrolide antibiotics for cystic fibrosis. Cochrane Database Syst Rev 2004, 2:CD002203.

74. Strickland SL, Rubin BK, Drescher GS, Haas CF, O'Malley CA, Volsko TA, Branson RD, Hess DR: AARC Clinical practice guideline: effectiveness of nonpharmacologic airway clearance techniques in hospitalized patients. Respir Care 2013, 58:2187-2193

75. Rubin BK: Designing clinical trials to evaluate mucus clearance therapy. Respir Care 2007, 52:1348-1361.

doi:10.1186/2213-0802-2-6

Cite this article as: Rubin: Secretion properties, clearance, and therapy

in airway disease. Translational Respiratory Medicine 2014 2:6.

\section{Submit your manuscript to a SpringerOpen ${ }^{\circ}$ journal and benefit from:}

- Convenient online submission

- Rigorous peer review

- Immediate publication on acceptance

- Open access: articles freely available online

- High visibility within the field

- Retaining the copyright to your article 